\title{
The Effect of Measuring Magnetic Susceptibility of Water Samples by Starting with Isothermal Remanent Magnetization (IRM) before Anhysteretic Remanent Magnetization (ARM)
}

\author{
Maureen Kapute Mzuza1,2*, Samwel Mchele Limbu ${ }^{3,4}$ \\ ${ }^{1}$ State Key Laboratory of Estuarine and Coastal Research, East China Normal University, Shanghai, China \\ ${ }^{2}$ Department of Lands, Mzuzu University, Mzuzu, Malawi \\ ${ }^{3}$ Department of Aquatic Sciences and Fisheries, University of Dar es Salaam, Dar es Salaam, Tanzania \\ ${ }^{4}$ Department of Biology, School of Life Sciences, Laboratory of Aquaculture Nutrition and Environmental Health, \\ East China Normal University, Shanghai, China \\ Email: " maureenmzuza@yahoo.com
}

Received 13 May 2015; accepted 22 June 2015; published 25 June 2015

Copyright $(2015$ by authors and Scientific Research Publishing Inc.

This work is licensed under the Creative Commons Attribution International License (CC BY).

http://creativecommons.org/licenses/by/4.0/

(c) (i) Open Access

\begin{abstract}
Estimating magnetic properties of water samples by first measuring the Anhysteretic Remanent Magnetization (ARM) before Isothermal Remanent Magnetization (IRM) is induced has been costly due to the discard of samples measured by staring with the latter before the former. However, no clear understanding exists on the effect of measuring magnetic properties values by first inducing IRM before ARM. This study explored the effect of measuring concentration related parameters $(\chi \mathrm{lf}, \chi \mathrm{fd}$ and $\chi \mathrm{ARM})$, a mineral related parameter $\left(S_{-300}\right)$ and grain size parameters $(\chi \mathrm{fd} \%$ and $\chi$ ARM/SIRM ratio) from water samples by starting with IRM before ARM. Forty three surface water samples were collected from the estuarine of Yangtze River (China) with the aim of measuring magnetic characteristics by starting with IRM before ARM. The results indicated that, measuring magnetic properties by either starting with ARM or IRM led to similar values for $\chi \mathrm{lf}, \chi \mathrm{fd}, \chi \mathrm{fd} \%$, $\chi A R M, S_{-300}$ and $\chi$ ARM/SIRM ratio $(p>0.05)$. These results imply that, measuring concentration related parameters does not necessarily require measuring ARM first and then IRM. Researchers can start by measuring any parameter between ARM and IRM without affecting the final results of the water samples, but with proper demagnetization when started with IRM.
\end{abstract}

\footnotetext{
${ }^{*}$ Corresponding author.
}

How to cite this paper: Mzuza, M.K. and Limbu, S.M. (2015) The Effect of Measuring Magnetic Susceptibility of Water Samples by Starting with Isothermal Remanent Magnetization (IRM) before Anhysteretic Remanent Magnetization (ARM). International Journal of Geosciences, 6, 614-618. http://dx.doi.org/10.4236/ijg.2015.66048 


\section{Keywords}

\section{$\chi$ fd, $\chi$ ARM, $\chi$ ARM/SIRM Ratio, Water Samples, Susceptibility Parameters}

\section{Introduction}

Measuring magnetic susceptibility is an important aspect in understanding the magnetic properties of water samples. The magnetic properties availed can be used to outline the status of an area such as pollution level and soil contamination with heavy metals [1]. Through the use of magnetic properties, it is also possible to trace the source of sediments affecting an area. Magnetic methods using geochemistry and mineral analysis have been utilized in measuring magnetic properties since 1980's [2]-[4]. The experimental study of magnetic materials requires a means of producing the field which will magnetize the material and a way of measuring the resulting magnetic effect on the material [5].

The common method for measuring magnetic properties of samples is to first measure the Anhysteretic Remanent Magnetization (ARM) before Isothermal Remanent Magnetization (IRM) is induced into the sample [6]. The preference of inducing first ARM revolves around the fact that, ARM is the magnetization which has been left behind in a ferromagnetic material after an external magnetic field is removed. Consequently, the procedure of inducing ARM first and measuring its value using magnetometer then detaching it using an alternating field (a.f) demagnetizer destroys the ARM. This process of demagnetization helps to return the remanence of the sample to zero. In so doing, ARM has been used as a useful laboratory technique for characterizing magnetic properties.

One of the limitations of this method is that many researchers discard samples when they make a mistake by starting measuring IRM before ARM with a fear that results obtained would be wrong. This has been costly to scientists because acquiring samples involves substantial amount of time and money. It has been advised for researchers to continue measuring the IRM and fully demagnetize the samples before measuring ARM [7]. However, no clear scientific explanation exists on the effect of measuring magnetic properties values by first inducing IRM before ARM. The aim of this study was therefore to explore the effect of measuring magnetic properties of water samples by starting with IRM before ARM. It was hypothesized that magnetic properties for the parameters measured would have significant different values when estimated by starting with IRM before ARM.

\section{Materials and Methods}

\subsection{Water Sample Collection and Analysis}

Surface water samples were collected from the estuarine of Yangtze River (China) with the aim of measuring magnetic characteristics. The normal procedure was followed: Membrane were numbered then weighted on beam balance. Water sample was filtered using a pump into jug through a plastic pipe. The sediments remained on the membrane was dried at a temperature below $40^{\circ} \mathrm{C}$ for 72 hours (3 days). After drying, the membrane was weighed again to determine the weight of the sediments by subtracting the weight of membrane from the total weight of membrane and sediment. Average total number of samples was 43 which included the spring tide and neap tide samples.

Following usual procedure, BartingtonMS2B magnetic susceptibility meter was used to find the low and high magnetic susceptibility. Samples magnetic properties were analyzed at low frequency susceptibility of $0.47 \mathrm{kHz}$ and high frequency susceptibility of $4.7 \mathrm{kHz}$ ( $\chi \mathrm{lf}$ and $\chi \mathrm{hf}$, respectively) [3] [8]-[10]. Frequency dependent susceptibility ( $\chi \mathrm{fd})$ was calculated as $\chi \mathrm{fd}=(\chi \mathrm{lf}-\chi \mathrm{hf})$. IRM was imparted at $1 \mathrm{~T}$ and then backfields at $-100 \mathrm{mT}$ and $-300 \mathrm{mT}$. Then the samples were demagnetized to zero before ARM was acquired in a $0.04 \mathrm{mT}$ direct current field superimposed on a peak AF demagnetization field of $10 \mathrm{mT}$ and $100 \mathrm{mT}$ [11].

\subsection{The Process of Demagnetization}

The same water samples were then demagnetized to zero. This was done by removing the samples from the sample holder, placing the sample membrane into another polyether paper (shaking) and then placing them back into the sample holder. Then these samples were put into Molspin and demagnetized to zero. The samples were 
left idle for two months. Thereafter, since the low frequency susceptibility ( $\chi$ lf) and high frequency susceptibility $(\chi \mathrm{hf})$ were already measured, the next step after demagnetization was acquiring ARM. ARM was acquired in a $0.04 \mathrm{mT}$ direct current field superimposed on a peak AF demagnetization field of $10 \mathrm{mT}$ and $100 \mathrm{mT}$, and expressed as susceptibility ( $\chi \mathrm{ARM}$ ) by normalizing ARM with dc field.

Isothermal Remnant Magnetization (IRM) was then imparted again at $1 \mathrm{~T}$ and then backfields at $-100 \mathrm{mT}$ and $-300 \mathrm{mT}$. This was done so that the results can be used for reference to the first IRM which was obtained at the beginning. Concentration related parameters $\left(\chi \mathrm{lf}, \chi \mathrm{fd}, \chi \mathrm{ARM}\right.$ and SIRM), mineral related parameter $\left(\mathrm{S}_{-300}\right)$ and grain size parameter ( $\chi \mathrm{ARM} / \mathrm{SIRM})$ were calculated to compare the results [2] [3] between samples measured by starting with IRM and those started with ARM. The values of $\chi \mathrm{fd}$ were estimated to reflect presence of fine viscous grains close to the super-paramagnetic (SP)/single domain (SD) boundary [3] [12]. The parameter $\chi \mathrm{ARM}$ was calculated for sensation of single domain ferromagnetic grains. The ratio of $\chi \mathrm{ARM} / \mathrm{SIRM}$ was then calculated to show variation trend of magnetic grain size of the samples [2] [3] [11] [13]. This was in line with calculations of $\mathrm{S}_{-300}$, which indicates the mineral assemblage variations between samples and it can be influenced by grain size variation in ferromagnetic minerals with higher SD grains coercivities than multidomain (MD) grains [14]-[16].

\subsection{Statistical Analyses}

Results are presented as mean \pm standard error of the mean (SDM) and data were tested for homogeneity of variances using Levene's test to avoid violating parametric test assumptions. After confirming homogeneity, two sample t-test was used to compare the means of $\chi \mathrm{lf}, \chi \mathrm{fd}, \chi \mathrm{fd} \%, \chi \mathrm{ARM}, \mathrm{S}_{-300}$, and $\chi \mathrm{ARM} / \mathrm{SIRM}$ ratio for samples measured by starting with IRM and ARM at $5 \%$ level of significance. All analyses were conducted using Statistical Package for Social Science (SPSS) for Windows version 20.

\section{Results}

The results on the magnetic properties measured by starting with IRM and then ARM are summarized in Table 1. The results indicated that, measuring magnetic properties by either starting with IRM or ARM led to similar values for $\chi \mathrm{lf}\left(t_{(84)}=0.010, \mathrm{p}=0.992\right), \chi \mathrm{fd}\left(t_{(84)}=-0.020, \mathrm{p}=0.984\right), \chi \operatorname{ARM}\left(t_{(84)}=-1.957, \mathrm{p}=0.054\right), \mathrm{S}_{-300}$ $\left(t_{(84)}=1.460, \mathrm{p}=0.148\right), \chi \mathrm{fd} \%\left(t_{(84)}=-0.293, \mathrm{p}=0.770\right)$ and the $\chi$ ARM/SIRM ratio $\left(t_{(84)}=1.631, \mathrm{p}=0.107\right)$.

\section{Discussion}

The results have indicated similar values for $\chi \mathrm{lf}, \chi \mathrm{fd}, \chi \mathrm{ARM}, \mathrm{S}_{-300}, \chi \mathrm{fd}(\%)$ and $\chi \mathrm{ARM} / \mathrm{SIRM}$ ratio between samples measured by starting with IRM and ARM. The similarity in $\chi \mathrm{lf}$ and $\chi \mathrm{fd}$ parameters shows that, the presence of fine viscous grains which were close to the super-paramagnetic (SP)/single domain (SD) boundary was not affected [17]. Fine viscous grains remained the same in both samples whether measured by starting with $\mathrm{ARM}$ or IRM. This is also applied to $\chi \mathrm{ARM}$ which was calculated to estimate the sensation of single domain ferromagnetic grains. Viscous grains are usually very intact in samples in such a way they are not altered by the

Table 1. The magnetic properties of samples measured by starting with Anhysteretic Remnant Magnetization (ARM) and Isothermal Remnant Magnetization (IRM) during the study period.

\begin{tabular}{ccc}
\hline \multirow{2}{*}{ Magnetic property } & \multicolumn{2}{c}{ Method of measurement } \\
\cline { 2 - 3 }$\chi_{\text {lf }}$ & Started with ARM & Started with IRM \\
$\chi_{\mathrm{fd}}$ & $111.54 \pm 22.53$ & $111.22 \pm 22.56$ \\
$\chi \mathrm{ARM}$ & $8.28 \pm 1.93$ & $8.33 \pm 1.93$ \\
$\mathrm{~S}_{-300}$ & $898.51 \pm 182.63$ & $1967.76 \pm 515.04$ \\
$\chi_{\mathrm{fd}}(\%)$ & $96.35 \pm 0.53$ & $94.94 \pm 0.81$ \\
$\chi$ ARM/SIRM & $7.47 \pm 0.66$ & $7.75 \pm 0.66$ \\
\hline
\end{tabular}

All values of the magnetic parameters measured were statistically similar $(\mathrm{p}>0.05)$. 
inducing ARM before IRM [18]. These results prove that the sensation was not affected in any way in both cases. These results imply that concentration related parameters may not be affected when magnetic susceptibility are measured by starting with IRM or ARM.

The mineral related parameter $\left(\mathrm{S}_{-300}\right)$ was also similar between samples measured by starting with IRM before inducing ARM. This parameter represents the water-rock interaction which plays a vital role for water chemistry in a particular area [19]. In general, water chemistry is determined by lithological influences, complex weathering process and ion exchange along with influence of ions from anthropogenic impact [19]. These factors are unaltered during measurement by starting with IRM or ARM. The similarity in $\mathrm{S}_{-300}$ indicates that mineral properties of water samples were not altered by either starting with ARM or IRM. Based on the current results, measuring magnetic properties by starting with IRM and then ARM may not affect mineral related parameters.

The values of $\chi \mathrm{fd} \%$ and $\chi \mathrm{ARM} / \mathrm{SIRM}$ ratio were calculated to show variation trend of magnetic grain size of the samples. The similarity in these parameters between the two methods of measurements helps to prove that even magnetic grain size was not affected in any way. This is in agreement with [13] who argued that $\chi$ ARM/ SIRM ratio is commonly used as a grain-size indicator of ferrimagnetic minerals which peaks in the single domain (SD) range and decreases with increasing grain size. Its value remains unaltered when measured by first imparting IRM or ARM. These results imply that, measuring $\chi \mathrm{fd} \%$, XARM and $\chi \mathrm{ARM} / \mathrm{SIRM}$ ratio do not necessarily require measuring ARM first and then IRM. These results show that the magnetic grain size parameters were the same and were not affected by the change in the method whether starting imparting IRM in samples and then demagnetize before imparting ARM. Researchers can start by measuring any parameter between ARM and IRM without affecting the final results of the samples.

In general, the results have indicated that it is possible to obtain similar values for $\chi \mathrm{lf}, \chi \mathrm{fd}, \chi \mathrm{ARM}, \mathrm{S}_{-300}, \chi \mathrm{fd}$ $(\%)$ and $\chi$ ARM/SIRM ratio between samples measured by starting with IRM and ARM. However, the experience of this experiment shows that, it is too involving and just wastage of time. In addition, sometimes it is not easy to be sure whether the samples have been completely demagnetized to zero or not. Therefore, to avoid wasting time and making mistakes, it is advisable to start with ARM and then finish by imparting IRM as proposed by [12]. However, in case by mistake someone has started imparting IRM before ARM, it is better to demagnetize the samples to zero and then impart the ARM. There is no need to throw away the samples because they can still be used with a caution that they are first demagnetized to zero before ARM measurements are taken. In this way, costs of time and money involved in obtaining samples are not wasted.

\section{Conclusion}

This study has shown that it is possible to start imparting IRM to samples before imparting ARM and obtain the same results as long as the samples are demagnetized to zero before imparting ARM. The only challenge is that it is too involving and time consuming. Moreover, the assurance that the samples have been demagnetized to zero is not a grantee. Therefore, it is better to follow the normal procedure of starting imparting ARM and finish with IRM to be assured of correct results. This approach may be helpful to researchers during laboratory analysis, because many researchers discard samples when they make mistakes by starting measuring IRM before ARM fearing that results obtained would be wrong, consequently costing more money to scientists to collect other samples. Thus, the results of this research will help many scientists including those in environmental magnetism.

\section{Acknowledgements}

The authors express their sincere thanks to the State Key Laboratory of Estuarine and Coastal Research (Project Number -344000-00546 and 44KZ001K) and graduate School of East China Normal University (ECNU) for supporting this study.

\section{References}

[1] Fialová, H., Maier, G., Petrovský, E., Kapička, A., Boyko, T. and Scholger, R. (2006) Magnetic Properties of Soils from Sites with Different Geological and Environmental Settings. Journal of Applied Geophysics, 59, 273-283. http://dx.doi.org/10.1016/j.jappgeo.2005.10.006

[2] Wang, H., Xu, L., Sun, X., Lu, M., Du, X., Huo, Y. and Snowball, I. (2011) Comparing Mineral Magnetic Properties of Sediments in Two Reservoirs in "Strongly" and "Mildly" Eroded Regions on the Guizhou Plateau, Southwest China: 
A Tool for Inferring Differences in Sediment Sources and Soil Erosion. Geomorphology, 130, 255-271. http://dx.doi.org/10.1016/j.geomorph.2011.04.003

[3] Zhang, W., Xing, Y., Yu, L., Feng, H. and Lu, M. (2008) Distinguishing Sediments from the Yangtze and Yellow Rivers, China: A Mineral Magnetic Approach. The Holocene, 18, 1139-1145. http://dx.doi.org/10.1177/0959683608095582

[4] Zhang, W., Yu, L., Lu, M., Hutchinson, S.M. and Feng, H. (2007) Magnetic Approach to Normalizing Heavy Metal Concentrations for Particle Size Effects in Intertidal Sediments in the Yangtze Estuary, China. Environmental Pollution, 147, 238-244. http://dx.doi.org/10.1016/j.envpol.2006.08.003

[5] Cullity, B.D. and Graham, C.D. (2011) Introduction to Magnetic Materials. John Wiley \& Sons, Hoboken.

[6] Walden, J., Slattery, M.C. and Burt, T.P. (1997) Use of Mineral Magnetic Measurements to Fingerprint Suspended Sediment Sources: Approaches and Techniques for Data Analysis. Journal of Hydrology, 202, 353-372. http://dx.doi.org/10.1016/S0022-1694(97)00078-4

[7] Shilton, V.F., Booth, C.A., Smith, J.P., Giess, P., Mitchell, D.J. and Williams, C.D. (2005) Magnetic Properties of Urban Street Dust and Their Relationship with Organic Matter Content in the West Midlands, UK. Atmospheric Environment, 39, 3651-3659. http://dx.doi.org/10.1016/j.atmosenv.2005.03.005

[8] Owens, P.N., Walling, D.E. and Leeks, G.J. (1999) Use of Floodplain Sediment Cores to Investigate Recent Historical Changes in Overbank Sedimentation Rates and Sediment Sources in the Catchment of the River Ouse, Yorkshire, UK. CATENA, 36, 21-47. http://dx.doi.org/10.1016/S0341-8162(99)00010-7

[9] Walling, D. (2005) Tracing Suspended Sediment Sources in Catchments and River Systems. Science of the Total Environment, 344, 159-184. http://dx.doi.org/10.1016/j.scitotenv.2005.02.011

[10] Wilkinson, S.N., Hancock, G.J., Bartley, R., Hawdon, A.A. and Keen, R.J. (2013) Using Sediment Tracing to Assess Processes and Spatial Patterns of Erosion in Grazed Rangelands, Burdekin River Basin, Australia. Agriculture, Ecosystems \& Environment, 180, 90-102. http://dx.doi.org/10.1016/j.agee.2012.02.002

[11] Hofman, J., Wuyts, K., Van Wittenberghe, S., Brackx, M. and Samson, R. (2014) Reprint of on the Link between Biomagnetic Monitoring and Leaf-Deposited Dust Load of Urban Trees: Relationships and Spatial Variability of Different Particle Size Fractions. Environmental Pollution, 192, 285-294. http://dx.doi.org/10.1016/j.envpol.2014.05.006

[12] Thompson, R. and Oldfield, F. (1986) Environmental Magnetism. Allen \& Unwin: Springer, London. http://dx.doi.org/10.1007/978-94-011-8036-8

[13] Maher, B.A. (1988) Magnetic Properties of Some Synthetic Sub-Micron Magnetites. Geophysical Journal International, 94, 83-96. http://dx.doi.org/10.1111/j.1365-246X.1988.tb03429.x

[14] Robinson, S.G. and Sahota, J.T. (2000) Rock-Magnetic Characterization of Early, Redoxomorphic Diagenesis in Turbiditic Sediments from the Madeira Abyssal Plain. Sedimentology, 47, 367-394. http://dx.doi.org/10.1046/j.1365-3091.2000.00298.x

[15] Yamazaki, T. (2009) Environmental Magnetism of Pleistocene Sediments in the North Pacific and Ontong-Java Plateau: Temporal Variations of Detrital and Biogenic Components. Geochemistry, Geophysics, Geosystems, 10, 1-18. http://dx.doi.org/10.1029/2009GC002413

[16] Yamazaki, T. and Ikehara, M. (2012) Origin of Magnetic Mineral Concentration Variation in the Southern Ocean. Paleoceanography, 27, 1-13. http://dx.doi.org/10.1029/2011pa002271

[17] Venkatachalapathy, R., Veerasingam, S., Basavaiah, N., Ramkumar, T. and Deenadayalan, K. (2011) Environmental Magnetic and Geochemical Characteristics of Chennai Coastal Sediments, Bay of Bengal, India. Journal of Earth System Science, 120, 885-895. http://dx.doi.org/10.1007/s12040-011-0108-z

[18] Dunlop, D.J. and Prévot, M. (1982) Magnetic Properties and Opaque Mineralogy of Drilled Submarine Intrusive Rocks. Geophysical Journal International, 69, 763-802. http://dx.doi.org/10.1111/j.1365-246X.1982.tb02774.X

[19] Venkatramanan, S., Chung, S., Park, N., Ramkumar, T. and Gnanachandrasamy, G. (2014) A Preliminary Investigation of Hydrogeochemistry, Metals and Saturation Indices of Minerals in Nakdong Surface Water and Adjacent Deltaic Groundwater Using WATEQ4F Geochemical Model. International Journal of Earth Sciences and Engineering, 7, 456466. 